\title{
INFLUÊNCIA DO ESPAÇAMENTO E DO ESTÁDIO DE DESENVOLVIMENTO DA PLANTA NA PRODUÇÃO DE BIOMASSA E VALOR NUTRICIONAL DE Tithonia diversifolia (HEMSL.) Gray
}

\author{
GUALBERTO, Ronan ${ }^{1}$ \\ SOUZA JÚNIOR, Oscar Francisco ${ }^{2}$ \\ COSTA, Nídia Raquel ${ }^{3}$ \\ BRACCIALLI, Caio Doretto ${ }^{4}$ \\ GAION, Lucas Aparecido ${ }^{4}$
}

\begin{abstract}
RESUMO: Tithonia diversifolia, conhecida como girassol mexicano apresenta alto potencial de utilização no Brasil, em função de sua a adaptação às condições de baixa fertilidade do solo, dos diversos tipos de uso e de seu elevado valor nutricional. Objetivou-se avaliar a produção de biomassa e o valor nutricional de Tithonia, em função de espaçamentos e estádios de desenvolvimento das plantas. Conduziu-se o experimento em Marília-SP em delineamento blocos casualizados, em esquema fatorial 3 x 3, em três repetições. Os tratamentos foram os espaçamentos E1: 0,50 x 0,75 m, E2: 0,75 x 0,75 m e E3: 1,0 x 0,75 m e os estádios de desenvolvimento das plantas (pré-floração, floração e pós-floração). A produção de biomassa fresca no menor espaçamento foi superior aos demais somente na pós-floração, já a produção de biomassa seca na pós-floração não apresentou diferenças entre E1 e E2, porém nestes a produção foi superior ao E3. Para os teores de PB, EE, FB, MM, celulose e lignina, a interação entre os tratamentos não foi significativa. Os espaçamentos não afetaram o teor de PB, porém na pré e pós-floração os valores foram superiores ao da floração. Para os teores de FB, MM e celulose ocorreram diferenças entre espaçamentos e estádios da planta e para a lignina, somente para estádios da planta. Para os teores de FDN e FDA ocorreu interação significativa entre os tratamentos. O menor teor de FDN foi obtido no E1 e na pré-floração, porém não diferiu estatisticamente do E2 e do estádio floração. Para o teor de FDA, os melhores resultados foram obtidos nos espaçamentos E2 e E3 e na pré-floração. Baseado na produção de biomassa e na análise bromatológica, conclui-se que principalmente no menor espaçamento e na pré-floração que o uso de Tithonia é uma alternativa promissora como suplementação protéica na alimentação animal.
\end{abstract}

Palavras-chave: Tithonia diversifolia. Forrageira arbustiva. Produção de biomassa. Valor nutricional.

\section{INFLUENCE OF SPACING AND PLANT DEVELOPMENT STADIUM IN BIOMASS YIELD AND NUTRITIONAL VALUE OF Tithonia diversifolia (HEMSL.) Gray}

\begin{abstract}
SUMMARY: Tithonia diversifolia, known as Mexican sunflower presents high use potential in Brazil, in function of its adaptation to soil low fertility, several kinds of use and of its high nutritional value. This work objectified to evaluate biomass yield and nutritional value of Tithonia, in function of spacings and plant development stadiums. Experimental scheme was conducted in Marília municipal district, Sao Paulo State, by using randomized complete blocks, in factorial scheme $3 \times 3$, in three replications. The treatments consisted of $\mathrm{E} 1: 0,50 \times 0,75 \mathrm{~m}, \mathrm{E} 2: 0,75 \times 0,75 \mathrm{~m}$ and E3: $1,0 \times 0,75 \mathrm{~m}$ and plants development stadiums (pre-flowering, flowering and post-flowering). Fresh biomass yield in the smallest spacing was superior to the others only in post-flowering stadium. In other way, dry biomass yield in the post flowering, didn't present differences between $\mathrm{E} 1$ and E2, even so in these situations, yield was superior to E3. For PB, EE, FB, MM, cellulose and lignin content, the interaction between treatments was not significant. Spacings didn't affect PB content, however in pre and post-flowering the values were superiors to those ones obtained from flowering stadium. For FB, MM and cellulose contents, significant differences were observed between spacings plant development stadiums and for

\footnotetext{
${ }^{1}$ Prof. Dr. Genética e Melhoramento de Plantas. Coordenador Engenharia Agronômica. Ciências Agrárias. UNIMAR - Universidade de Marília.ronan@flash.tv.br

${ }^{2}$ Mestrando em Agronomia (Produção Vegetal). UNIMAR - Universidade de Marília.

${ }^{3}$ Mestranda em Agronomia (Sistemas de Produção). UNESP - Campus Ilha Solteira

${ }^{4}$ Acadêmico do Curso de Engenharia Agronômica da UNIMAR. Universidade de Marília.
} 
lignin, only for plants stadiums. For FDN and FDA contents occurred significant interaction between treatments. The smallest FDN content was obtained in E1 spacing and in pre-flowering stadium, but it didn't differ statistically from E2 and from flowering stadium. For FDA content, the best results were obtained in E2 and E3 spacings and in pre-flowering stadium. Based on the biomass yield and in bromatologic analysis, it was possible to conclude that mainly in the smallest spacing and in pre-flowering stadium, Tithonia use is a promising alternative as supplementation in animal feeding.

Keywords: Tithonia diversifolia. Fodder plant. biomass yield. Nutritional value.

\section{INTRODUÇÃO}

Recentemente tem surgido um crescente interesse na busca de recursos alimentícios que possam substituir parcialmente o uso de concentrados na alimentação animal ou para recuperar solos degradados, tornando menos oneroso o custo de produção, principalmente para os pequenos produtores. As plantas arbóreas e arbustivas têm um papel preponderante por seu elevado valor nutritivo e natureza multipropósito, existindo ainda muitas espécies com boas propriedades forrageiras, entre as quais se destacam as leguminosas por excelência. No entanto, existem outras espécies perenes com grande potencial que não têm sido utilizadas de maneira extensiva. Dentro desse numeroso grupo pode-se citar a Tithonia diversifolia que é uma planta herbácea da família Asteraceae, originária da América Central (NASH, 1976). Posteriormente foi introduzida em diversos países da África, Ásia e América do Sul, onde recebe diversas denominações, como girassol mexicano, boldo japonês, margaridão amarelo, dentre outros (ROIG; MESA, 1974; RIOS, 1993; WANJAU et al., 1998).

Há evidências de que plantas de Tithonia diversifolia acumulam nitrogênio em suas folhas tanto quanto as leguminosas, têm altos níveis de fósforo, um grande volume radicular, uma habilidade especial para recuperar os escassos nutrientes do solo, uma ampla faixa de adaptação e toleram condições de acidez e baixa fertilidade do solo. É uma espécie considerada rústica, podendo suportar podas ao nível do solo ou mesmo queimadas (WANJAU et al., 1998). Além disso, apresenta boa capacidade de produção de biomassa, rápido crescimento e baixa demanda de insumos e de manejo para seu cultivo (RIOS, 1998).

Os usos relatados da Tithonia diversifolia incluem, alimentação animal, adubo verde, atração de insetos, cerca viva e quebra vento, atividade farmacológica, atividade alelopática e fitoterápica, entre outros.

Em uma avaliação realizada sobre o conteúdo de nutrientes de Tithonia diversifolia (folhas, pecíolos, flores e caule até 1,5 cm de diâmetro), em cinco fases de desenvolvimento, Navarro e Rodriguez (1990), encontraram que a matéria seca variou de 13,5 a 23,23\% e a proteína bruta oscilou entre 14,84 e $28,75 \%$, sendo que os valores mais baixos de proteína foram encontrados em estádios avançados da floração (89 dias), enquanto que na fase de 
crescimento inicial (30 dias) e de prefloração (50 dias), se encontraram os valores mais altos de proteínas. Os conteúdos de proteínas obtidos se encontram dentro dos valores encontrados por Devendra (1992), para folhas de 12 espécies de árvores (14 - 36,6\%) e por Benavides (1994) em uma série de dados compilados de 24 espécies arbóreas e 22 arbustivas (10,9 a $42,4 \%)$.

Comparando o valor médio de proteína bruta encontrado por Navarro e Rodríguez (1990) em Tithonia diversifolia, com os encontrados por Rosales (1996), em três das espécies arbóreas mais utilizadas para a alimentação de ruminantes na Colômbia, Gliricidia sepium (14,7\%), Leucaena leucocephala (22,2\%) e Erytrina poeppigiana $(21,4 \%)$, pode considerarse que seu conteúdo de proteína, se encontra com um valor alto dentro das espécies forrageiras utilizadas para alimentação de ruminantes.

O teor de proteína bruta encontrado por Navarro e Rodríguez (1990) tem sido ratificado por Solarte (1994), 18,9\%; Vargas (1994), 21-25\%; Rosales (1996), 24,2\%; Premarante et al. (1998), 28\%; Wanjau et al. (1998), 28,75\% e Medina e Carreño (1999), 22,07\%; Sorria et al. (1999), 21-28\%. Rosales (1996) ainda determinou que 16,6\% da proteína bruta das folhas foi solúvel em água, valor este superior ao obtido para Leucaena leucocephala $(14,8 \%)$.

De acordo com Mahecha (2002), Tithonia diversifolia é uma das espécies não leguminosas considerada, como promissora para utilização na alimentação de diferentes espécies animais, em especial de ruminantes. Nos últimos anos sua utilização na alimentação animal tem aumentado. Há relatos de seu uso em vacas leiteiras (MAHECHA e ROSALES, 2005; MAHECHA et al., 2007), ovelhas (Vargas, 1992, citado por MAHECHA et al., 2007; PREMARATNE et al., 1998), búfalos (PREMARATNE, 1990), cabras (WAMBUI et al., 2006).

Odunsi et al. (1998), avaliaram a influência de folhas de Tithonia diversifolia na dieta de galinhas poedeiras, tanto no desenvolvimento das aves quanto na qualidade dos ovos e concluíram que esta espécie mostrou um grande potencial de uso em galinhas poedeiras, recomendando-se utilizá-la na faixa de $15 \%$ da dieta. Resultados semelhantes foram obtidos por Susana e Tangendjaja (1988) que concluíram que a proteína foliar concentrada de Tithonia diversifolia pode ser usada em rações de aves de granja até $20 \%$ sem efeitos adversos. Em outro trabalho, Medina et al. (1999), numa análise conduzida para avaliar as folhas de Tithonia diversifolia como uma fonte econômica em potencial de xantofilas para alimentação comercial de aves domésticas demonstrou que esta é uma espécie que se enquadra nos requisitos, principalmente pela presença de xantofilas dihidroxiladas na proporção de $48,33 \%$. 
Tithonia diversifolia tem sido utilizada na área agrícola, como adubo verde para melhoria dos solos e como atração de insetos em algumas culturas; na apicultura, como fonte de néctar; na área médica, como fitoterápico contra diversos males como hepatite e algumas infecções; na área nutricional, como complemento alimentar para animais.

As informações sobre o seu valor nutritivo e alimentício são escassas, no entanto, os estudos reportados, permitem fazer inferências sobre seu potencial de uso. Em termos gerais, sua folhagem se caracteriza por apresentar boa aceitabilidade e altos teores de proteína, devido a várias razões, entre elas, seu conteúdo de nitrogênio, fósforo e a sua rápida degradabilidade e fermentação a nível ruminal.

Como no Brasil nenhum trabalho foi realizado com essa espécie, na área agropecuária, o objetivo deste trabalho foi avaliar a produção de biomassa e o valor nutricional de Tthonia diversifolia, em função de espaçamentos e estádios de desenvolvimento das plantas.

\section{MATERIAL E MÉTODOS}

O experimento foi conduzido em condições de campo, na Fazenda Experimental Marcelo Mesquita Serva, da Universidade de Marília, situada no município de Marília - SP. geograficamente localizado em latitude $22^{\circ} 12^{\prime} 50^{\prime \prime} \mathrm{S}$ e longitude $49^{\circ} 56^{\prime} 45^{\prime \prime} \mathrm{W}$, a uma altitude de, aproximadamente, $610 \mathrm{~m}$, em relação ao nível do mar, no período de março a setembro de 2006.

O clima da região é correspondente a Cwa, segundo a classificação de Köppen, ou seja, mesotérmico tropical úmido com três meses mais secos (Junho, Julho e Agosto) e com concentração de chuvas no verão.

O solo da área experimental foi caracterizado morfologicamente como Argissolo Vermelho Amarelo, com declividade média ao redor de 10\% (relevo levemente ondulado).

A análise foi realizada pelo Laboratório de Análises Agronômicas da Fundação Shunji Nishimura, localizado no município de Pompéia - SP, cujos resultados são apresentados na Tabela 1.

Tabela 1 - Resultado da análise química de solo da área experimental ( 0 a $20 \mathrm{~cm}$ ).

\begin{tabular}{|c|c|c|c|c|c|c|c|c|c|c|}
\hline $\begin{array}{c}\mathrm{pH} \\
\mathrm{CaCl}_{2}\end{array}$ & $\begin{array}{c}\mathrm{MO} \\
\mathrm{g} \mathrm{dm}^{-3}\end{array}$ & $\begin{array}{c}\mathrm{P} \\
\mathrm{mg} \mathrm{dm}\end{array}$ & $\mathrm{K} \quad \mathrm{Ca}$ & $\begin{array}{l}\mathrm{Mg} \mathrm{H}+\mathrm{Al} \\
\mathrm{mmol}_{\mathrm{c} .} \mathrm{dm}^{-3}\end{array}$ & SB & $\bar{T}$ & $\begin{array}{l}\mathrm{V} \\
\%\end{array}$ & $\mathrm{Ca} / \mathrm{Mg}$ & $\mathrm{Ca} / \mathrm{K}$ & $\mathrm{Mg} / \mathrm{K}$ \\
\hline 6,5 & 18 & 61 & $\begin{array}{ll}1,3 & 28\end{array}$ & 13 & 38 & 50 & 76 & 3,0 & 13,0 & 4,3 \\
\hline
\end{tabular}

Foram utilizadas estacas de Tithonia, retiradas da parte basal ( mais lignificada) O terço médio dos ramos de plantas que foram plantadas em área próxima, em 21/10/2005 
(153 dias de idade). As estacas foram padronizadas com aproximadamente $30 \mathrm{~cm}$ de comprimento e em seguida foram plantadas.

O delineamento experimental utilizado foi o de blocos casualizados em esquema fatorial $3 \times 3$, com três repetições. As fontes de variações foram três espaçamentos E1: 0,50 x 0,75 m, E2: 0,75 x 0,75 m e E3: 1,00 x 0,75 m e três estádios de desenvolvimento das plantas (pré-floração, floração e pós-floração).

Cada parcela foi constituída de cinco linhas com dez plantas cada. A área útil foi constituída de dez plantas centrais, onde foram coletados todos os dados.

Foi feito o preparo do solo através de uma grade aradora. Logo em seguido foi feito o plantio das estacas de acordo com os espaçamentos pré estabelecidos, em 23/03/2006. As estacas foram colocadas na posição vertical, enterrando cerca de 1/3 de seu comprimento. Na área não foi feita calagem nem adubação de plantio e nem cobertura. Até a brotação das estacas foram feitas irrigações periódicas. Os demais tratos culturais consistiram de duas capinas manuais.

O primeiro corte foi realizado em 05/07/2006 (plantas com 103 dias de idade), constituindo o estádio de pré-floração, o segundo corte no dia 08/08/2006, constituindo o estádio de floração e o terceiro corte em 19/09/2007, constituindo o estádio de pós-floração.

Após a coleta de 10 plantas, foram separadas as folhas, hastes e flores (quando presentes) e pesadas separadamente. Foram retiradas amostras de folhas, haste e flores para secagem em estufa de ar forçado a $65^{\circ} \mathrm{C}$, até peso constante (72 horas) para determinação da biomassa seca.

Foram avaliados: proteína bruta $(\mathrm{PB})$, extrato etéreo (EE), Matéria mineral (MM), fibra bruta (FB), fibra em detergente ácido (FDA), fibra em detergente neutro (FDN), celulose e lignina.

Para a avaliação da composição bromatológica da Tithonia, foram efetuadas as seguintes determinações: $O$ teor de PB foi obtido pela multiplicação da porcentagem de nitrogênio total encontrada pelo fator 6,25 , sendo que o nitrogênio total foi determinado pelo método micro-Kjeldahl (TEDESCO, 1982); o EE ou graxa, foi obtido da amostra tratada com éter de petróleo a $60^{\circ} \mathrm{C}$; a $\mathrm{MM}$ ou cinzas, pelo aquecimento da amostra a uma temperatura de 550 a $600{ }^{\circ} \mathrm{C}$ em uma mufla, ou seja, até o aquecimento ao rubro; a FB, resíduo insolúvel em ácido e álcalis que se perde durante a incineração a $500{ }^{\circ} \mathrm{C}$ e, FDA, FDN, lignina e celulose foram obtidos pelo método descrito por Van Soest (1965);

A análise bromatológica foi realizada no Laboratório de Análises Bromatológicas do Departamento de Melhoramento e Nutrição Animal da FMVZ/UNESP de Botucatu.

Os dados obtidos foram submetidos à análise de variância, através do programa 
computacional SISVAR (FERREIRA, 2000), utilizando-se o teste de Scott-Knott (1974) a $5 \%$ de probabilidade para comparação das médias.

\section{RESULTADOS E DISCUSSÃO}

Os dados da produção de biomassa fresca e seca da parte aérea da Tithonia encontramse na Tabela 2. Ocorreram diferenças significativas entre os espaçamentos e entre os estádios de desenvolvimento da planta, sendo que a interação também foi significativa para ambas as características.

Para o menor espaçamento $(0,50 \times 0,75 \mathrm{~m})$ as produções de biomassa fresca e seca no estádio de pós-floração foram superiores às obtidas no estádio de floração e, as obtidas neste estádio superiores às obtidas no estádio de pré-floração. No espaçamento intermediário $(0,75$ x $0,75 \mathrm{~m}$ ), as produções de biomassa fresca e seca também foram superiores no estádio de pós-floração, porém não diferiram nos estádios de pré-floração e floração. Já no maior espaçamento (1,00 X 0,75 m), não ocorreram diferenças estatísticas entre pós-floração e floração para ambas características.

Somente no estádio de pós-floração a produção de biomassa fresca no menor espaçamento foi superior aos demais, entretanto, para a produção de biomassa seca esta não diferiu estatisticamente do espaçamento intermediário. De maneira geral houve uma tendência de maior produção nos menores espaçamentos.

Tabela 2. Influência da interação entre espaçamentos e estádios de desenvolvimento das plantas sobre a produção de biomassa fresca (BF) e seca (BS), em t ha ${ }^{-1}$ de Tithonia diversifolia.

\begin{tabular}{|c|c|c|c|}
\hline \multirow{2}{*}{$\begin{array}{l}\text { Espaçamentos } \\
(\mathrm{m})\end{array}$} & \multicolumn{3}{|c|}{ Estádios da Planta } \\
\hline & Pré-Floração & Floração & Pós-Floração \\
\hline & \multicolumn{3}{|c|}{$\mathbf{B F}\left(\mathrm{t} \mathrm{ha}^{-1}\right)$} \\
\hline $0,50 \times 0,75$ & $17,57 \mathrm{aC}$ & $37,42 \mathrm{aB}$ & $83,25 \mathrm{aA}$ \\
\hline $0,75 \times 0,75$ & $17,72 \mathrm{aB}$ & $21,20 \mathrm{aB}$ & $66,79 \mathrm{bA}$ \\
\hline $1,00 \times 0,75$ & $14,23 \mathrm{aB}$ & $29,74 \mathrm{aA}$ & $43,24 \mathrm{bA}$ \\
\hline \multirow[t]{2}{*}{ C.V. (\%) } & & 28,33 & \\
\hline & \multicolumn{3}{|c|}{ BS $\left(\mathrm{t} \mathrm{ha}^{-1}\right)$} \\
\hline $0,50 \times 0,75$ & $3,43 \mathrm{aC}$ & $8,97 \mathrm{aB}$ & $19,74 \mathrm{aA}$ \\
\hline $0,75 \times 0,75$ & $3,55 \mathrm{aB}$ & $5,30 \mathrm{aB}$ & $17,88 \mathrm{aA}$ \\
\hline $1,00 \times 0,75$ & $3,53 \mathrm{aB}$ & $8,57 \mathrm{aA}$ & $10,47 \mathrm{bA}$ \\
\hline
\end{tabular}

Médias seguidas de mesma letra minúscula na coluna e maiúscula na linha não diferem entre si no nível de $5 \%$ de probabilidade pelo teste de Scott-Knott.

Os valores encontrados neste experimento estão dentro da faixa dos valores 
alcançados por Navarro e Rodríguez (1990), Rios (1997), Wanjau et al. (1998) e Sarria et al. (1999). Rios e Salazar (1995), avaliando a Tithonia diversifolia nos mesmos espaçamentos adotados neste estudo, porém realizando apenas um corte aos 110 dias do plantio, encontraram valores semelhantes; 82, 57 e $47 \mathrm{t} \mathrm{ha}^{-1}$ de biomassa fresca, correspondendo aos espaçamentos de 0,5 x 0,75 m, 0,75 x 0,75 m e 1,0 x 0,75 m, respectivamente. Entretanto, foram superiores aos obtidos por Ramírez et al. (2005). Estes autores testando três espaçamentos diferentes $(0,5 \times 1,0 \mathrm{~m}, 0,75 \times 1,0 \mathrm{~m}$ e $1,0 \times 1,0 \mathrm{~m})$, visando determinar o rendimento ( $\mathrm{kg}$ de $\mathrm{MS} \mathrm{ha}^{-1}$ ) de Tithonia diversifolia, na região Centro-Norte de Yucatán (México), encontraram a maior produção com a densidade mais alta (5.450 kg de MS ha ${ }^{-1}$ ).

Já uma pesquisa realizada em nove localidades de Quênia, abrangendo 257 ha de cultivo de Tithonia, estimou-se que esta espécie tem potencial de produção de biomassa de 530 toneladas de massa fresca, correspondendo a 84,8 toneladas de MS ha ${ }^{-1}$ ano (RESEARCH REPORT, 2000).

Na Tabela 3, são apresentadas as médias para os teores de PB, EE, FB, MM, celulose e lignina, em função dos espaçamentos e estádios de desenvolvimento da planta. Para a PB, os diferentes espaçamentos não influenciaram os valores encontrados, porém nos estádios da planta de pré-floração e pós-floração os teores foram superiores ao estádio de floração. Estes resultados não estão de acordo com o encontrado por Navarro e Rodriguez (1990), que verificaram que a proteína bruta da Tithonia oscilou entre 14,84 e 28,75\%, sendo que os valores mais baixos de proteína foram encontrados em estados avançados da floração (89 dias). Entretanto, estes autores avaliaram as folhas, flores e hastes com até $1,5 \mathrm{~cm}$ de diâmetro.

Tabela 3. Teores de proteína bruta (PB), extrato etéreo (EE), fibra bruta (FB), matéria mineral (MM), celulose e lignina de Tithonia diversifolia em função de espaçamentos e de estádios de desenvolvimento das plantas.

\begin{tabular}{ccccccc}
\hline $\begin{array}{c}\text { Espaçamentos } \\
(\mathrm{m})\end{array}$ & PB & EE & FB & MM & Celulose & Lignina \\
\hline E1 & $12,28 \mathrm{a}$ & $2,98 \mathrm{a}$ & $33,69 \mathrm{a}$ & $13,03 \mathrm{a}$ & $36,38 \mathrm{a}$ & $7,49 \mathrm{a}$ \\
E2 & $11,74 \mathrm{a}$ & $2,77 \mathrm{a}$ & $30,00 \mathrm{~b}$ & $13,09 \mathrm{a}$ & $32,25 \mathrm{~b}$ & $6,76 \mathrm{~b}$ \\
E3 & $12,46 \mathrm{a}$ & $2,34 \mathrm{a}$ & $32,99 \mathrm{a}$ & $11,28 \mathrm{~b}$ & $32,71 \mathrm{~b}$ & $8,94 \mathrm{a}$ \\
\hline Estádios & & & & & & \\
\hline Pré-Floração & $12,35 \mathrm{a}$ & $2,92 \mathrm{a}$ & $29,84 \mathrm{~b}$ & $14,06 \mathrm{a}$ & $30,95 \mathrm{~b}$ & $8,53 \mathrm{a}$ \\
Floração & $10,31 \mathrm{~b}$ & $2,76 \mathrm{a}$ & $33,38 \mathrm{a}$ & $12,48 \mathrm{~b}$ & $35,70 \mathrm{a}$ & $7,96 \mathrm{a}$ \\
Pós-Floração & $13,81 \mathrm{a}$ & $2,41 \mathrm{a}$ & $33,46 \mathrm{a}$ & $10,86 \mathrm{c}$ & $34,98 \mathrm{a}$ & $7,20 \mathrm{a}$ \\
\hline C.V. $(\%)$ & 11,95 & 25,87 & 8,54 & 8,33 & 9,24 & 17,99 \\
\hline
\end{tabular}

Médias seguidas de mesma letra na coluna não diferem entre si ao nível de 5\% de probabilidade pelo teste de Scott-Knott. 
Comparando o valor médio de proteína bruta encontrado por Navarro e Rodríguez (1990) em Tithonia diversifolia, com os encontrados por Rosales (1996), em três das espécies arbóreas mais utilizadas para a alimentação de ruminantes na Colômbia, Gliricidia sepium (14,7\%), Leucaena leucocephala (22,2\%) e Erytrina poeppigiana (21,4\%) e, com os encontrados por Nozella (2001), em diversas espécies com potencial forrageiro no Brasil, Alfafa (20,4\%), Feijão guandu (13,8\%), feno de leucena (17,6\%0, sesbânia (18,7\%) e Gliricídia (21,3\%), pode-se considerar que seu conteúdo protéico, se encontra com um valor alto dentro das espécies forrageiras utilizadas para alimentação de ruminantes.

Além do estádio vegetativo, influenciar o teor de PB das plantas, como mencionado por Navarro e Rodriguez (1990), esse teor varia de acordo com a relação folha-caule (RIOS e SALAZAR, 1995). Mesmo assim, Os teores de PB na MS obtidos neste estudo estão bem acima daqueles exigidos para suprir a necessidade de bovinos adultos (9\%), conforme Cavalheiro e Trindade (1992), e garantir o consumo voluntário de MS (acima de 7\%), segundo Milford e Minson (1966).

O teor de EE não foi influenciado pelos espaçamentos nem pelos estádios de desenvolvimento das plantas (Tabela 3). Observa-se que os teores variaram de 2,34 a 2,98\%, valores que estão acima dos obtidos por Navarro e Rodriguez (1990) e Rosales (1996), porém inferiores aos obtidos por Premarante et al. (1998), 3,25\%; Sarria (1999), 6,00\% e Wambui et al. (2006), 3,25\%. Já Medina e Carreño (1999), analisando a composição química de folhas de Tithonia, encontraram 8,12\%. De acordo com Burgos et al. (2006) o EE ou lipídeos totais, quando elevados nos alimentos pode torna-los rançosos, e em conseqüência redução de seu valor nutricional. Afirmam ainda, que no caso dos ruminantes, se deve monitorar o conteúdo de EE na ração para evitar que exceda 6-8\% de lipídeos na mesma.

A análise de variância dos teores de FB, MM e celulose indicou significância $(\mathrm{P}<0,05)$ para diferença entre espaçamentos e estádios da planta e para a lignina, somente para estádios da planta. Para essas características não houve efeito significativo da interação.

O teor de FB foi maior, no menor espaçamento $(33,69 \%)$, porém não diferiu estatisticamente do maior espaçamento $(32,99 \%)$ ao passo que nos estádios da planta ele foi inferior $(29,84 \%)$ no estádio de pré-floração. Na literatura são encontrados valores menores para o teor de FB em Tithonia (MEDINA; CARREÑO, 1999; SARRIA et al., 1999), porém eles analisaram somente as folhas. De acordo com Burgos et al. (2006) a análise de FB é uma referência muito pobre dos componentes fibrosos dos alimentos e que a mesma tem sido substituída por outras análises mais precisas, que permitem uma melhor descrição e/ou caracterização desta fração nos alimentos e que permitam uma melhor interpretação biológica dos processos de digestão e se relacionam melhor com os resultados in vivo. 
O teor de $\mathrm{MM}$ em relação a espaçamentos foi inferior somente no maior (E3), com $11,28 \%$, enquanto para os estádios da planta a pré-floração apresentou maior valor $(14,06 \%)$ e a pós-floração o menor (10,86\%) (Tabela 3). Estes valores encontrados para a Tithonia podem ser considerados altos, o que provavelmente é um indicativo de alta concentração de minerais como relata Kwabiah et al. (2003). Burgos et al. (2006), relatam que o teor de MM de um alimento normalmente é menor que $10 \%$ na matéria seca e, comentam ainda, que na folhagem de dezenas de árvores forrageiras analisadas foram poucas que excederam este valor.

Nozella (2001) estudando treze plantas com potencial forrageiro, entre elas, alfafa, feijão guandu, gliricídia, leucena e sesbânia, através da análise bromatológica nenhuma delas apresentou teor de MM superior a 8,0\%.

O teor de celulose foi superior no espaçamento menor $(0,50 \times 0,75 \mathrm{~m})$, enquanto nos estádios da planta, os maiores teores de celulose foram observados na floração e pós-floração (Tabela 3), sendo que os teores variaram de 30,95 a 36,38\%.

Consultando a literatura a respeito do teor de celulose em outras forrageiras, verificamos que Ladeira et al. (2001) obtiveram 38,1\% em Stylosanthes guianensis, em Gliricidia sepium foi observada uma faixa de 22 a 24,4 \% (SMITH; VAN HOUTERT, 1987), no capim-elefante, de 31,65 a 33,19\% e em capim-mombaça, de 28,95 a 33,80\% (CLIPES et al., 2006), no milho e no girassol, 27,00\% e 31,90\%, respectivamente (POSSENTI et al., 2005). Observa-se que os valores obtidos para a Tithonia não estão fora da faixa dos valores obtidos para algumas leguminosas e gramíneas. De acordo com Van Soest (1994) a celulose é o polissacarídeo mais abundante da natureza e principal constituinte da maioria das paredes celulares, exceto de algumas sementes, e que o seu teor varia de 20 a $40 \%$ na MS de plantas superiores.

Os valores médios do teor de lignina encontrados na Tabela 5, mostram que somente para espaçamentos ocorreram diferenças significativas, sendo que no espaçamento intermediário $(0,75 \times 0,75 \mathrm{~m})$ o teor de lignina foi inferior aos demais. Os teores variaram de 6,76 a $8,94 \%$ e estão

A lignina, reconhecidamente é um dos principais componentes responsáveis pela queda da digestibilidade dos nutrientes das plantas forrageiras (VAN SOEST, 1963; JUNG; VOGEL, 1986). Forbes (1995) comenta que existem muitos tipos de fibras na maioria das forragens e que a lignina, que é indigestível, está inversamente relacionada com a digestibilidade, mas não há uma relação consistente dela com o consumo voluntário. De acordo com Norton (1982) a lignina está presente nas partes lenhosas dos vegetais, sabugos, cascas e folhas e corresponde a 5 a $10 \%$ do peso seco das forragens, podendo atingir até $50 \%$ na madeira de lei. 
Os teores de lignina encontrados neste estudo estão abaixo dos observados para algumas leguminosas. Smith e Van Houtert (1987) citam valores para a Gliricidia sepium, no intervalo de 7,7 - 12,7\%. Ladeira et al. (2001) trabalhando com Stylosanthes guianensis obtiveram um teor de 11,8\%, para a alfafa são relatados valores, variando de 9,9 a 12,9\% (KAWAS et al. 1990; FOSTER et al., 1991), enquanto para a Leucaena leucocephala Burgos et al. (2006) obtiveram um teor médio de 15,1\%, quando analisaram folhas e talos tenros.

A análise de variância dos teores de FDN e FDA na MS indicou significância $(\mathrm{P}<0,01)$ para diferença entre espaçamentos e estádios da planta para a FDN e $(\mathrm{P}<0,05)$ para a FDA. Ocorreu interação significativa para os dois fatores estudados (Tabela 4).

Ball et al. (1991) estabeleceram que os valores de FDN são correlacionados negativamente com o consumo voluntário de forragem pelo animal, enquanto FDA, com a digestibilidade.

O menor teor de FDN (50,48\%) foi obtido no menor espaçamento e na pré-floração, porém não diferiu estatisticamente do espaçamento intermediário e do estádio floração (52,08\% e 53,62\%, respectivamente). Os valores encontrados neste estudo estão acima dos encontrados na literatura para esta espécie, porém na maioria deles foi avaliado somente o teor de FDN das folhas, como é o caso de Rosales (1996), 35,3\%; Mahecha e Rosales (2005), 24,05\%; Wambui et al. (2006), 26,63\% e Mahecha et al. (2007), 37,57\%

Entretanto, os valores obtidos aqui para a FDN são inferiores aos obtidos para algumas leguminosas, tais como para a alfafa, 59,5\% (KAWAS et al., 1990); Stylosanthes guianensis, 63,7\% (Ladeira et al., 2001); guandu, 70,40\%; mucuna preta, 71,39\% ; crotalária, 67,16\%; leucena, 75,59\% (NASCIMENTO e SILVA, 2004). Burgos et al. (2006) relata valores de FDN para a leucena de 51,1\% e Nozella (2001) relata valores de 63,92\% para o guandu, $57,02 \%$ para a sesbânia e 40,75\% para a gliricídia.

Tabela 4. Influência da interação entre espaçamentos e estádios de desenvolvimento das plantas sobre a fibra detergente neutro (FDN) e fibra detergente ácido (FDA) de Tithonia diversifolia.

(Continua)

\begin{tabular}{cccc}
\hline $\begin{array}{c}\text { Espaçamentos } \\
(\mathrm{m})\end{array}$ & \multicolumn{3}{c}{ Estádios da Planta } \\
\hline & Pré-Floração & Floração & Pós-Floração \\
\hline & & FDN $(\%)$ \\
\hline E1 & $50,48 \mathrm{bB}$ & $53,62 \mathrm{bB}$ & $66,32 \mathrm{aA}$ \\
E2 & $52,08 \mathrm{bB}$ & $61,07 \mathrm{aA}$ & $64,02 \mathrm{aA}$ \\
E3 & $65,22 \mathrm{aA}$ & $65,47 \mathrm{aA}$ & $63,56 \mathrm{aA}$
\end{tabular}


Tabela 4. Influência da interação entre espaçamentos e estádios de desenvolvimento das plantas sobre a fibra detergente neutro (FDN) e fibra detergente ácido (FDA) de Tithonia diversifolia.

(Conclusão)

\begin{tabular}{|c|c|c|c|}
\hline \multirow[t]{2}{*}{ C.V. (\%) } & \multicolumn{3}{|c|}{5,11} \\
\hline & & FDA $(\%)$ & \\
\hline E1 & $42,00 \mathrm{aB}$ & $46,29 \mathrm{aA}$ & $49,49 \mathrm{aA}$ \\
\hline E2 & $40,15 \mathrm{aA}$ & $40,70 \mathrm{bA}$ & $40,29 \mathrm{bA}$ \\
\hline E3 & $40,91 \mathrm{aB}$ & $45,96 \mathrm{aA}$ & $40,73 \mathrm{bB}$ \\
\hline C.V. (\%) & & 5,81 & \\
\hline
\end{tabular}

Médias seguidas de mesma letra minúscula na coluna e maiúscula na linha não diferem entre si ao nível de $5 \%$ de probabilidade pelo teste de Scott-Knott.

Para o teor de FDA, que se correlaciona negativamente com a digestibilidade, os melhores resultados foram obtidos nos espaçamentos E2 e E3 e no estádio da planta de préfloração (Tabela 4). Os teores variaram de 40,15\% a 49,49\%, sendo que estes valores, assim como comentado para a FDN estão acima dos valores relatados na literatura para esta espécie, em função de que neste estudo analisou-se a planta inteira e não somente as folhas. Mesmo assim, estes valores são considerados razoáveis para a alimentação de ruminantes.

\section{CONCLUSÃO}

Em face dos resultados obtidos foi possível obter as seguintes conclusões:

a) maior produção de biomassa fresca e seca foi obtida no menor espaçamento e no estádio pós-floração;

b) o teor de proteína bruta obtido pode ser considerado bom, considerando que foi determinado de toda a parte aérea;

c) os teores de FDN e FDA encontrados estão dentro da faixa dos indicados para a nutrição animal;

d) a análise bromatológica indicou que a Tithonia diversifolia apresenta um alto valor nutritivo, podendo ser uma alternativa na alimentação animal.

\section{REFERÊNCIAS}

BALL, D.M.; HOVELAND, C.S.; LACEFIELD, G.D. Southern forages. Atlanta: Potash \& Phosphate Institute, 1991. 256p.

BENAVIDES, J. E. Árboles y arbustos forrajeros en América Central. Centro Agronômico Tropical de Investigación y Enseñanza, CATIE, 1994, v. 1 e 2, 721p. (Série Técnica. Informe Técnico, 236) 
BURGOS, A.A.et al. Composición química-nutricional de árboles forrajeros. Cuerpo Académico de Producción en Agroecosistemas tropicales. Mérida, Yucatán, México. 2006. $56 \mathrm{p}$.

CAVALHEIRO, A.C.L.; TRINDADE, D.S. Os minerais para bovinos e ovinos criados em pasto. Porto Alegre: Sagra/DC Luzzato, 1992, 142p.

CLIPES, R.C.et al. Composição químico-bromatológica da forragem durante o período de ocupação em pastagens de capim-elefante (Pennisetum purpureum, Schum) e capimmombaça (Panicum maximum, Jacq) sob manejo rotacionado. Arq. Bras. Med. Vet. Zootec., v.58, n.5, p.868-876, 2006.

DEVENDRA, C. Nutritional potential of fodder trees and shrubs as protein sources in ruminant nutrition. In: SPEEDY, A.W.; PUGLIESE, P.L. Legume trees and other fodder trees as protein source for livestock. FAO Animal Production and Health Paper, v. 102, n. 102, p. $95-113,1992$.

FERREIRA, D.F. Análises estatísticas por meio do Sisvar para Windows versão 4.0. In: REUNIÃO ANUAL DA REGIÃO BRASILEIRA DA SOCIEDADE INTERNACIONAL DE BIOMETRIA. 45., 2000, São Carlos. Anais... São Carlos: UFSCar, 2000. p. 255-258.

FORBES, J.M. Voluntary food intake and diet selection in farm animals. Chap. 10. CAB internacional, 1995.

FOSTER Jr., L.A. et al. Apparent digestibility and nutrient balance in lambs fed different levels of flatpea hay. Journal Animal Science, v.69, p.1719-1725, 1991.

JUNG, H.G. Forage lignins and their effects on fiber digestibility. Agronomy Journal, v.81, p.33-38, 1989.

JUNG, H.G.; VOGEL, K.P. Influence of lignin on digestibility of forage cell wall material. Journal of Animal Science, v.62, p.1703-1712, 1986.

KAWAS, J.R., JORGENSEN, N.A., LU, C.D. Influence of alfalfa maturity on feed intake and site of nutrient digestion in sheep. J. Anim. Sci., v.68, p.4376-4386, 1990.

KWABIAH, A.B.et al. Response of soil microbial biomass dynamics to quality of plant materials with emphasis on P availability. Soil Biology \& Biochemistry, v.35, n.2, p.207216,2003

LADEIRA,M.M.et al. Consumo e digestibilidades aparentes total e parciais do feno de Stylosanthes guianensis. Arquivo Brasileiro de Medicina Veterinária e Zootecnia, v. 53, n. 2, 2001.

MAHECHA, L. Valor nutricional y utilización del Botón de Oro Tithonia diversifolia en la alimentación animal. In: TRES especies vegetales promisorias: Nacedero (Trichanthera gigantea), Botón de Oro (Tithonia diversifolia), Bore (Acacia macrorrhiza). Cali: CIPAV, 2002. p. 237-255. 
MAHECHA, L.et al. Tithonia diversifolia (hemsl.) Gray (botón de oro) como suplemento forrajero de vacas F1 (Holstein por Cebú). Livestock Research for Rural Development , v. 19, n. 2, 2007.

MAHECHA, L.; ROSALES , M. Valor nutricional del follaje de Botón de Oro (Tithonia diversifolia [Hemsl]. Gray), en la producción animal en el trópico. Livestock Research for Rural Development, v. 17, n. 9, 2005.

MEDINA, M. L. B.; CARREÑO, R. J. D. Evaluation del material foliar de rayo de sol comoposible fuente de xantofilas. Agronomia Tropical, v. 49, p. 373-390, 1999.

MILFORD, R.; MINSON, D.J. Intake of tropical pasture species. In: CONGRESSO INTERNACIONAL DE PASTAGENS, 9, 1965, São Paulo. Anais... São Paulo: Alarico, 1966. p.815-822.

NASCIMENTO, J.T.; SILVA, I. de F. da . Avaliação quantitativa e qualitativa da fitomassa de leguminosas para uso como cobertura de solo. Ciência Rural, v. 34, n. 3, p. 947-949, 2004.

NASH, D. Flora de Guatemala. Fieldiana: Botany, v. 24, Parte XII, p. 323-325, 1976.

NAVARRO, F.; RODRÍGUEZ, E. F. Estudio de algunos aspectos bromatológicos del Mirasol (Tithonia diversifolia Hemsl y Gray) como posible alternativa de alimentación animal. 1990. Tesis (Universidad del Tolima). Ibagué, Tolima.

NORTON, B.W. Differences between species in forage quality. In: HACKER, J.B. (ed.). Nutritional limits to animal production from pastures. Farnham Royal: Commonwealth Agricultural Bureaux, 1982. p.89-110.

NOZELLA, E.F. Determinação de taninos em plantas com potencial forrageiro para ruminantes. 2001. 58p. Dissertação (Mestrado) CENA/USP. Piracicaba.

ODUNSI, A.A.; FARINU, G.O.; AKINOLA, J.O. Influence of dietary wild sunflower (Tithonia diversifolia) leaf meal on layers performance and egg quality. Nigerian Journal of animal production, v. 23, v. 1-2, p. 28-32, 1996

POSSENTI, R.A.et al. Parâmetros bromatológicos e fermentativos de silagens de milho e girassol. Ciência Rural, v. 35, n. 5, p. 1185-1189, 2005.

PREMARATNE, S. Effect of non-protein nitrogen and fodder legumes on the intake, digestibility and growth parameters of buffaloes. Domestic buffalo production in Asia. Proceedings of the final research co-ordination meeting on the use of nuclear techniques to improve domestic buffalo production in Asia - phase II, 20-24 February 1989, Rockhampton, Australia, organised by the joint FAO-IAEA Division of Nuclear Techniques in Food and Agriculture. 1990.

PREMARATNE, S.et al. Effects of type and level of forage supplementation on voluntary intake, digestion, rumen microbial protein synthesis and growth in sheep fed a basal diet of rice straw and cassava. Asian Australasian Journal of Animal Sciences, v. 11, n. 6, p. 692696, 1998. 
RAMÍREZ, R.U.et al. Efecto de la altura de corte, densidad de siembra y tipo de suelo en la producción de Tithonia diversifolia. In: REUNIÓN ALPA, 19. México: Tampico, 2005. p. 38.

RESEARCH REPORT, 022. Using Tithonia as an organic fertilizer. Sustainable Agriculture Centre for Research and Development in Africa, 2000. 10p.

RIOS, C. I. Botón de oro Tithonia diversifolia (Hemls.) Gray . In: CIPAV. Arboles e arbustos forrajeros utilizados en alimentación animal como fuente proteica. Centro para la Investigación en Sistemas Sostenibles de Producción Agropecuária: CIPAV, p. 115-126, 1997.

RÍOS, C. I. Efecto de la densidad de siembra y altura de corte sobre la producción de biomassa del bóton de oro Tithonia diversifolia (Hemsl) Gray, evaluada en cortes sucesivos. Investigación, validación y capacitación en Sistemas Agropecuarios Sostenibles. Convenio CETEC - IMCA - CIPAV. Informe de Avance. Cali. p. 81-83. 1993.

RÍOS CI. 1998. Tithonia diversifolia (Hemsl.) Gray, una planta con potencial para la producción sostenible en el trópico. CONFERENCIA ELECTRÓNICA DE LA FAO-CIPAV SOBRE AGROFORESTERÍA PARA LA PRODUCCIÓN ANIMAL EN LATINOAMÉRICA. Artículo n.14.

RIOS, C,I.; SALAZAR, A. Tithonia diversifolia (Hemsl.) Gray, una fuente proteica alternativa para el tropico. Liverstock Research For Rural Development, v. 6, p. 75-87, 1995.

ROIG, J. T.; MESA, A. Plantas Medicinales, aromáticas e venenosas de cuba. La Habana, 1974, p. 709.

ROSALES, M. In vitro assessment of the nutritive value of mixtures of leaves from tropical fodder trees. 1996. 214p. Tese (Doctorado of Plant Sciences) - Oxford University, Oxford, UK.

SARRIA, P.; ROSERO, P.M.; MURGUEITIO, E.R. Desarrollo de Sistemas ostenibles de Producción de cerdos usando recursos tropicales disponibles al nivel de finca. CIPAV y SINTAP PRONATTA, Cali, 1999. 100p.

SCOTT, A.J.; KNOTT, M.A. A cluster analysis method for grouping means in the analysis of variance. Biometrics, v. 30, n. 2, p. 507-512, 1974.

SMITH, O. B.; VAN HOUTERT, M. F. J. The feeding value of Gliricidia sepium: a review. World Animal Review, Roma, n. 62, p. 57-62, 1987.

SOLARTE A. Experiencias de investigación participativa en sistemas de Producción Animal en dos zonas del Valle del Cauca. In: SEMINARIO INTERNACIONAL DESARROLLO SOSTENIBLE DE SISTEMAS AGRARIOS, 3. Memórias... Cali p. 49 - 72. 1994.

SUSANA, I.W.R.; TANGENDJAJA, B. Leaf protein concentrates: calopogonium caeruleum and Tithonia diversifolia. In: SEMINAR NASIONAL PETERNAKAN DAN FORUM PETERNAK "UNGGAS DAN ANEKA TERNAK" KE DUA. BOGOR (Indonesia). Proceedings... BALITNAK, p. 190-202, 1988. 
TEDESCO, M.J. Extração simultânea de P, K, Ca e Mg em tecido de plantas por digestão com $\mathbf{H}_{2} \mathbf{O}_{2}-\mathbf{H}_{2} \mathbf{S O}_{4}$. Porto Alegre: Universidade Federal do Rio Grande do Sul, 1982. 23p.

(Informativo Interno, 1)

VAN SOEST, P.J. Nutritional Ecology of the Ruminant. Ithaca: Comstock, 1994. 476 p.

VAN SOEST, P.J. Symposium on factors influencing the voluntary intake in relation to chemical composition and digestibility. Journal Animal Science, v.24, n.3, p.834-843, 1965.

VAN SOEST, P.J. Use of detergents in the analysis of fibrous foods. II. A rapid method for the determination of fibre and lignin. Journal of the Association of the Official Analytical Chemists, v.46, p.829-835, 1963.

VARGAS, J. E. Caracterización de recursos forrajeros disponibles en tres agroecosistemas del Valle del Cauca. In: SEMINÁRIO INTERNACIONAL DESARROLLO SOSTENIBLE DE SISTEMAS AGRARIOS, 2. Maestría en Sistemas Sostenibles de Producción Animal en los Trópicos. Memorias... 1994. p. 135-149.

WAMBUI, C.C.; ABDULRAZAK, S.A.; NOORDIN, Q. The effect of supplementing urea treated maize stover with Tithonia, Calliandra and Sesbania to growing goats. Livestock Research for Rural Development, v. 18, n. 5, article \#64, 2006.

WANJAU, S.; MUKALAMA J.; THIJSSEN, R. Transferencia de biomasa: Cosecha gratis de fertilizante. Boletin de ILEIA, p. 25. 
